\title{
'Years after the course': dialogues with mid-career practitioners about the resilience of professional learning from a higher education CPD programme
}

\author{
Joy Northcott, University of Edinburgh
}

\begin{abstract}
This article discusses a small-scale qualitative research study which examined the mid-career reflections of English as a Foreign Language (EFL) teachers about their earlier training on the post-graduate in-service Diploma in English Language Teaching to Adults (DELTA) programme. Participants offered observations on their experience which varied from extremely positive to highly critical, but most were able to testify to at least some continuing value of their earlier professional training. Some continued to make extensive use of techniques originally learned on the DELTA, decades later, whereas others were less convinced about the long-term value of their training experience. In this article four key factors are identified which appear to be associated with greater resilience of learning: the kind of motivation which participants brought to the course; the capacity of students and tutors to generate a "community of learning"; the course as a fully integrated learning experience; and post-course consolidation.
\end{abstract}

Key words: teacher education; teacher learning; impact; DELTA; retrospective study

\section{Introduction}

Impact and effectiveness of Continuing Professional Development (CPD) programmes for teachers is a much-researched area. Some writers in the field of teacher education have taken the view that in-service professional development has little impact on practice. Roberts (1998), Fullan (2001) and Freeman (1992), amongst others, question the impact of professional development experiences. Knight et al (2006), investigating professional development in Higher Education, emphasise non-formal learning over event-based learning. Eraut states 'The evidence that subsequent practice is affected by CPE (Continuing Professional Education) is scanty and more often negative than positive' (1994, 25).

Other writers conclude differently, however. Powell et al (2003), Cope et al (1992), Davies and Preston (2002), Bird et al (2005), Burchell et al (2002) and Williams (2005), for example, when discussing longer (master's) courses, report more positive views. There is perhaps a difference between shorter, top-down, agenda-led CPD events which, according to many writers, do not show demonstrable changes, and those which are longer, more comprehensive and accredited, often offered by HE institutions, such as degree and diploma courses, and which do appear to effect positive change.

But what makes in-service development programmes effective? A brief foray into the literature of in-service teacher education, both EFL and general education, suggests that effective programmes should do the following: 
- Adopt a broadly social constructivist approach (Roberts, 1998; Singh and Richards, 2006) and value existing knowledge (Hayes, 1995).

- Include learning experiences which are: experiential (Waters, 2006), co-operative (Hayes, 1995; Singh and Richards, 2006), task-based (Hayes, 1995), interactive (Knowles, 1996; Wenger, 1999).

- Contain ideas relevant to participants' teaching context(s) (Waters, 2006; Hayes, 1995).

- Include coaching/support (Rhodes and Hoghton-Hill, 2000; Hayes, 1995).

- Include follow-up (Day, 1999; Hayes, 1995; Waters, 2006; Waters and Vilches, 2000).

These ideas point towards the need for a community of learning, for a sense of integration in terms of theory and practice, and for post-course consolidation.

Day (1999) suggests that another factor is also important: participants' readiness, in career, intellectual or emotional terms, to take the course. Research into in-service master's courses for teachers (Johnston, 1994; Bird et al, 2005) reports a variety of motivations for embarking on a professional development course. Some can be classed as 'internal', such as a wish to improve teaching skills, whereas others are extrinsic, such as the ambition to find a better job. Knight et al (2006) outlined four different types of motivation: critical incident, professional (extrinsic), interpersonal, professional (intrinsic). Ryan and Deci (2000) distinguish between extrinsic and intrinsic motivation, but also between different forms of extrinsic motivation. Extrinsic motivation has often been seen as a poorer form of motivation but Ryan and Deci (ibid) describe it as a continuum, depending on the degree to which the factors are self-determined, stating that the effect of some forms of extrinsic motivation can be remarkably similar to the effect of intrinsic motivation.

\section{Aims}

This article reports a study in the area of CPD for teachers of English as a foreign language (TEFL). The TEFL Diploma (DELTA) is a post-graduate in-service qualification, classed as Level 7 on the new National Qualifications Framework and equivalent to 60 credits. It is offered at a range of educational establishments: at universities, colleges and other institutions, such as the British Council. The DELTA is taken by many EFL teachers in order to enhance their career prospects; the decision of whether, when and where is in the hands of each individual teacher. Despite parallels with master's courses, DELTA is nevertheless not purely academic since it combines theoretical assignments with practical assessed teaching.

The over-arching question in this study was 'In what ways did TEFL teachers experience their Diploma course, perceived retrospectively?' In other words, the research aimed to explore professional learners' retrospective views of their in-service Diploma course, specifically:

- their reasons for taking the course

- their learning experience during the course

- their perspectives on the impact of this HE experience.

Many research studies report on perceptions of teacher education courses; for the most part, their aim is to determine the impact of the course. This research study investigated not only the 
perceived impact of the Diploma course but also teachers' perceptions of the course in order to weigh up the possible relationships between these factors.

\section{Methodology}

I explored the topic of teachers' perceptions of the Diploma course by constructing a case study since this enabled me to investigate the perceptions in some depth (Gomm et al, 2000; Gillham, 2000). The case was investigated through the use of several stages of qualitative, semistructured, individual interviews. I chose qualitative interviewing since a method was needed which allowed for the exploration of individual perceptions, for unforeseen issues to arise, and the freedom to discuss memories and feelings (Powney and Watts, 1987; McDonough and McDonough, 1997; Patton, 2002). It was the richness of communication available through qualitative interviewing (Gillham, 2000) that I wished to tap into for the purposes of this research.

A further reason for using interviews concerned the retrospective nature of the investigation and the fact that it depended to a large extent on memories of the past. This data was generally not forthcoming immediately; it took a process of facilitated exploration. Talking about one image often sparked off other memories, especially with probing and exploration on the part of the interviewer, and these came flooding back to life. It is debatable whether a questionnaire which, although having the advantage of reaching a greater number of people (Drever, 1995), does not carry the distinctive feature of live interchange at the point of data collection and would therefore perhaps not have generated the same vividness of memories and therefore the same quality of data.

With regard to retrospective recall, an investigation into subjects' perspectives on their earlier professional education presupposes that they have sufficient recall of that experience to fuel such perspectives. In theory, it would be possible to find subjects who had insufficient recollection of their Diploma for any useful connections to be made between the course and their subsequent teaching. The literature, however, is not so pessimistic. Powell (1985) was able to generate extensive data based on graduates' recall of learning experience. Bennett (1999) asked subjects to reflect on formative educational experiences across a time gap of up to forty-five years, and found that all his subjects could do this. Harmer (1988) looked at the retrospective experience of nine TEFL graduates and claimed that most teachers still had powerful memories even after some time.

In terms of the research design, I started with a series of five-minute mini-interviews, asking thirteen EFL teachers about their Diploma courses; the purpose at this stage was to explore the general nature of the issues. The themes arising were then taken as a basis for the pilot study, where in-depth, thirty-minute semi-structured interviews were undertaken with four more interviewees. Modifications were then made for the main study which comprised interviews with twenty EFL teachers. Since the research focused on the resilience and durability of learning, these interviewees were chosen according to the length of post-Diploma teaching experience they had; some participants had taken their Diploma only one year prior to the interview, others had taken it more than twenty years before, and others fell at regular intervals in between. The interview data was analysed using a Grounded Theory approach, following Strauss and Corbin (1998), in order to come up with a thematic categorisation of the data. 


\section{Findings}

\section{Impact}

The findings from this research study, although tentative and small-scale, are optimistic about the long-term value of CPD in the chosen field. The perspective of the majority was that the impact of this HE experience on their professional learning was substantial, sustained and relevant to subsequent teaching practice, and in many instances it was possible to suggest tentative links between what had made the experience life-changing or otherwise.

The five main areas of impact found in the data extended to: (a) propositional knowledge; (b) practical classroom aspects; (c) personal and psychological aspects; (d) organisational aspects; and (e) aspects relating to the wider TEFL profession. This is in line with Davies and Preston (2002), Williams (2005) and Burchell et al (2002), studies which investigated the effect of HE study on in-service teacher learning, particularly since the DELTA study reported changes in practical classroom teaching; although the classroom changes discussed in the DELTA study were more comprehensive and detailed than those mentioned in these other studies. Cope et al, (1992) and Powell et al, (2003), however, did not report impact of HE study on classroom practice.

The impact described by interviewees in the DELTA study was sometimes delayed, a finding in accord with Freeman (1989) and Knight et al (2006). In terms of the areas which lasted the longest, change in classroom practice was the area cited as being most durable. One interviewee reported:

One thing that's still with me from that time is it was frowned upon to use a coursebook in class... everything had to be made from scratch.... I still feel this need to change the book, adapt it and I'm sure that's where I got it from. So, years after the course, I'm still left with that, good or bad.

For those who had taken their course more recently, affective changes were still influential, but for those for whom a greater time had elapsed, the remaining effects of the Diploma course were evident in classroom practice.

The study set out to explore teachers' perceptions of their in-service HE study. In determining the nature, type and resilience of impact perceived by participants, four key factors appeared to be associated with greater depth and resilience of learning; these are outlined below. Depth of impact was defined as changes which were perceived as personal, fundamental and sustained, such as changes in beliefs and values or a changed teaching persona. One person said, for example:

It changed me... It made me focus less on the students as pals and more on what they needed to learn from the language. Before the course I'd think 'We'll do all these activities and they'll learn'. But after it: 'This is what they need and you've got to be quite careful about what you do and how you do it. 


\section{Motivation}

Participants were asked about their reasons for taking the Diploma course. Their motivation fell into three categories: extrinsic motivation relating to institutions; extrinsic motivation for personal reasons; and intrinsic motivation. Examples are shown in Figure 1 below:

\begin{tabular}{l} 
A. Institution-related \\
extrinsic reasons \\
- My school pushed me \\
to do it. \\
- My school encouraged \\
me to do it. \\
- Our school gave us a \\
financial incentive. \\
- My school decided to \\
run the course so I did \\
it because it happened \\
to be available. \\
\hline
\end{tabular}

Figure 1: Different motivations given for taking the course

A key finding with regard to motivation in this study was that those who gave intrinsic reasons ultimately described deeper and more sustained outcomes. One interviewee described her motivation:

I was ready for it, because I had got to that stage in my career when I really wanted to know more about teaching.

Then later, described the outcomes of the course:

It revolutionised my teaching completely. I was a completely different person in the classroom.

She reported that, even after fifteen years, she was still using approaches and techniques that she had learned on the Diploma course. Hers is not a lone example. This suggests, albeit tentatively, that if intrinsic motivation is present at the beginning of the course of study, the chances that it will have impact on teaching in a deeper way are good. This appears to confirm Ryan and Deci's claim that 'intrinsic motivation results in high-quality learning' $(2000,55)$.

Where intrinsic motivation was absent or unacknowledged, deep impact was possible but less predictable. A key issue here was receptivity to learning: those who cited intrinsic reasons for taking the course were almost, by definition, receptive to learning from the outset. Those whose arrival on the programme was for extrinsic reasons, often had to develop this 'receptivity' during the course. One particular participant was typical of this group. She started the course with extrinsic motivation, but she reported a number of key changes: a changed teaching persona, 
changed teaching approaches, and a feeling that the course had been a key professional development experience. It therefore appears to be possible to embark on a professional development course without being aware of any 'readiness' in terms of a personal, intrinsic need for development, but still gain enormous benefit. This teacher expressed her own surprise at this:

It was funny, because I didn't really even expect or want anything. Before I did it, I thought 'I have to do this because I have to get this qualification... to be able to get a permanent job'. But when I did the course, I really loved it. I think I'm probably quite unusual. ... It was like a double bonus - I was doing this for job reasons but I really liked it a lot.

One reason for the multiplicity of outcomes could be the type of extrinsic motivation that this group of interviewees held. Each professed a mixture of at least three different extrinsic reasons (more than other people starting from the same point). This provides powerful support for Ryan and Deci's point (2000) that some forms of extrinsic motivation are more self-determined than others and may achieve outcomes on a par with intrinsic motivational factors.

Receptivity to learning can come about for various reasons. In this Diploma study every person who mentioned readiness or receptivity showed a psychological 'readiness'. Some related readiness to career motivation:

It's to do with you being ready, as a professional, to be developed more.... I suppose also how into teaching you are as well, and how much you want to go on with it.

There were other kinds of psychological readiness, one which related to 'being in a rut', as is shown in the following example which suggests that an awareness of stagnation had prompted receptivity towards new learning:

I was in a rut, teaching-wise. I'd had about 7 years' experience, and I thought I was reasonably okay but I seemed to be doing the same things all the time.

A third type of readiness related to 'the signals being right':

I was absolutely ready for that type of experience and that type of theory, and that level of theory and that level of challenge. I drank it all in. It was just the right thing at the right moment.

This person had been teaching for only two years, so was perhaps just emerging from the novice, survival stage (Berliner, 1994) into the stabilization stage (Huberman, 1995) of teaching and therefore felt ready for new learning.

Although psychological readiness appeared to be related to three different aspects (career motivation, being in a rut, and a feeling that the 'time was right'), these all stem from the fact that these interviewees were in-service teachers, all of whom realised that there was more to come in terms of learning. It was a realisation they reached themselves, rather than being pushed, a realisation that can only come through an awareness of their own practice, often not present in the early stages of teaching. This highlights the role of reflection in reaching a stage of receptivity. Not only is reflection significant in the learning process; it can also propel professionals towards further learning. 
It is possible that the Diploma teachers who discussed their readiness for learning had some awareness that they no longer were, or wished to be, 'novice' or 'advanced beginner' teachers (Berliner, 1994), and that they were therefore receptive to change. This bears out Day's notions that people who have emerged from the novice stage of their careers do seek and benefit from wider perspectives on teaching $(1999, \mathrm{p} 150)$. It is also possible that those respondents who were mainly extrinsically motivated were still ready for further study but that they had not reached that stage of self-awareness. Further research relating to readiness, motivation and receptivity to learning might help to shed more light on such concepts.

One factor appears not necessarily to link with particular 'depth' of outcome, i.e. taking a course simply because it is on offer. Several interviewees reported holding this motivation, and they all perceived the changes in their teaching to be minimal. Their motivation is similar to the 'less self-determined' of Ryan and Deci's extrinsic factors (2000), which do not suggest powerful change. These interviewees pointed to certain modifications as a result of the course, but each mitigated this with comments suggesting that learning was either temporary or superficial. One summarised the lack of changes thus:

So he could introduce these fairly mainstream EFL ideas then we went back into the classroom and we had to basically forget about that because it didn't work.... So yes, a temporary reskilling, for the purposes of passing the exam.

\section{A community of learning}

Pre-course factors alone did not appear sufficient to promote impact; factors related to the course itself were also reported by participants as being of importance. The interview data suggested a number of different pathways leading to learning on the Diploma course, each of which involved or was mediated by other people, suggesting that the notion of a learning community as part of their HE study was significant to them. Highly favoured modes of learning were: discussion, interaction, experiential learning, reflection, mentoring, modelling, observing other people teaching, and receiving constructive feedback on teaching practice. Despite the fact that the DELTA course is a post-graduate HE study programme, transmission of propositional knowledge in lecture form was not favoured by any of the professional learners in this study. One participant reported:

There were one or two sessions with one tutor which were a little bit like a warmed-up instant meal.... because it was all written down what the content was to be...It didn't come over with any degree of spontaneity. It felt like going through it, hard to take it in, because you had to keep pinching yourself and tell yourself 'This might be useful. Think why!

This person clearly found difficulty perceiving the relevance of lecture delivery of pre-defined content. Another also found 'lecture style' off-putting:

She did all the boring... she was really into the theory, she did it in lecture style. Maybe that's what put me off all the theory of it... it was her standing at the front telling us...she could have done more interactive things, using us more, letting us talk more. 
A preference for an interactive style of learning is consistent with literature in the area of andragogy: Knowles (1996), for example, advocates activities which are interactive, participatory and experiential, in order to draw benefit from adult learners' life experience. Wenger also suggests that learning involves interaction with a social community (1999).

An interactive approach may have been particularly significant in the present study for several reasons. Firstly, the participants were adult learners and in-service teachers, and had considerable prior experience to bring to the course. Secondly, they were all language teachers; in current EFL thinking, it is difficult to develop language skills in learners using anything but an interactive methodology so they were probably all teaching interactively themselves.

Fellow course participants were also seen as crucial to a successful DELTA learning community. On a face-to-face course with very little lecture-style teaching and substantial task-based, experiential and reflective activity the other course participants can play a significant role in the learning process. What comes through very strongly in the data is that good experiences of fellow participants enhanced the learning considerably. Over half of the interview sample mentioned positive experiences of group learning; many cited this as being one of the main factors which influenced the impact of the course on their subsequent teaching. As the context of TEFL is widely distributed, this may have been due to the diverse teaching backgrounds of the other members, and the cross-pollination of ideas resulting from this diversity. Studying in the company of a range of people who have taught in a variety of countries/contexts encourages a very fertile learning environment. Eraut's notion that co-learners in a CPD arena 'bring different knowledge and perspectives' $(1994,13)$ is particularly pertinent to the Diploma course.

A number of people remembered discussions both inside and outside class and many valued them:

I liked doing the course with other teachers. I hadn't had so many opportunities to talk to people in that way before and learn from other people.

This is a typical example of several such quotations, suggesting that this was the first time that tacit, intuitive knowledge was being articulated. Becoming part of a community of practice and a community of learning was clearly perceived as an important source of learning. This suggests that learning on the DELTA course followed a social constructivist form of knowledge development with co-learners scaffolding each other's learning.

For the interviewees the Diploma course meant coming to an educational experience in the role of learner instead of teacher, and a number reported initial trepidation in returning to HE study. Several appreciated the learning which arose from sharing books, discussing ideas and sources for assignments and studying together for the final examination. This resonates with Eraut's notions of co-operative learning: 'share burdens of finding, scanning and degutting learning resources...' (1994, 13) and supports the claims by Hayes (1995) and Singh and Richards (2006) that EFL in-service teacher learning should take place in co-operative learning communities.

\section{A fully-integrated learning experience}

As well as creating a community of learning, many participants also reported that the course provided an integrated learning experience, a notion which can be conceptualised in several 
ways. First of all, the different aspects of the course were well linked. A number of interviewees made comments along these lines:

I liked learning new things in the theory sessions, like task-based learning or different error correction techniques, then trying them out in the classroom with learners in the teaching practice sessions.

Secondly, the learning which took place during the in-service study programme was reported by a large majority of participants as building on their previous teaching experience. There were many comments made about the role of prior experience, such as 'it links / builds / relates to / draws on / makes sense / fall into place', all of which suggest a sense of integration. These expressions support the view of a dynamic process, such as social constructivism, rather than a transmission view of teacher learning.

Participating in the Diploma course after they have already been teaching gave teachers the chance to take stock of their teaching to date. Many made comments which reflected this:

It made the teaching I'd done so far fall into place'

'It made all my teaching make sense.

The experience of the Diploma course therefore provided teachers with an opportunity to evaluate their own experience, and confirmed and clarified their practice. This is shown in the form of a backwards arrow in Figure 2 below.

As well as the course shedding light on pre-course teaching, the process works in reverse (the forwards arrow in Figure 2 below). In other words, pre-course teaching enables an understanding of the course content, facilitating an integration of practice and theory. This supports Singh and Richards' claim (2006) that in-service teacher learning should draw on previous teaching experience. In the eyes of several Diploma interviewees, an understanding of the course is dependent on pre-course experience:

It draws very much on your experience. All the written assignments draw on what you know and the learners you're used to teaching, and the materials you're used to using....It's very much an in-service course...You can't really benefit from it without several years' experience.

The practical experience provides a tool for understanding the theory. There were several moments when interviewees explained how the course content made sense to them in the light of their teaching, the following being particularly pertinent examples:

- And I'd think to myself 'Oh yes! I understand why that's a good idea because I can relate it to so-and-so in my teaching

- It was like a curtain taken off my eyes ...it made sense. What they said was so true and I thought, from what I'd observed in my classroom, I thought 'God, yes, of course!

This demonstrates that teachers need to bring something to the process in order to anchor the new learning. The pre-course teaching experience provides the basis in which to integrate new 
knowledge. It is possible, and perhaps indeed crucial, for participants to use prior teaching experience to make sense of course content, to envision their prior practice as they learn the theory, and to apply new ideas to known experience. Thus the personal/tacit theory is a means to understand the public/formal theory, and the latter is interpreted in the light of existing understanding.

\section{Post-course consolidation}

Post-course factors also appeared to have some bearing on how/whether changes took place as a result of the Diploma programme. Two interviewees mentioned that in subsequent jobs they were not able to use the knowledge and skills they had acquired during the course; both felt they were not taken any more seriously by their employers and that they were not given enough challenge. One recommended that:

Managers should realise that new Diploma candidates are bursting with knowledge and energy.

The energy released by achieving the Diploma needs to be harnessed and channelled thoughtfully by managers, in order to support the teacher and consolidate their learning and motivation. Both were disappointed, as the Diploma had been an important step in their careers and they quickly left their first post-Diploma posts, one stating:

It was very non-DELTA and that was one of the reasons I didn't renew my contract there, because I felt that, teaching-wise, it was soul-killing especially after the investment in the DELTA.

One interviewee had been very motivated and enthusiastic about the course but did not report many sustained outcomes. His main post-Diploma job had been in a context where the Diploma content was not deemed suitable ('Why did I bother doing the DELTA if I'm doing this kind of work?') and that his work since then had been part-time. This suggests again that the impact of the course might be dependent on post-course consolidation in the kind of job that provides the opportunity to use the course material.

\section{Conclusion}

The DELTA programme provides a fundamentally optimistic picture of CPD, in line with researchers such as Powell et al (2003), Bird et al (2005), Williams, R. (2005) and Burchell et al (2002), and underlines the fact that HE learning can have a significant role to play in the professional in-service learning of teachers. The large majority of interviewees benefited considerably from their study programme; the apparent resilience and durability of learning which they reported as part of this study may be connected to a developmental sequence of factors: motivation; a community of learning; an integrated learning experience; post-course consolidation.

The DELTA programme is based on a PRACTICE - THEORY - PRACTICE model, as shown in Figure 2 below. 


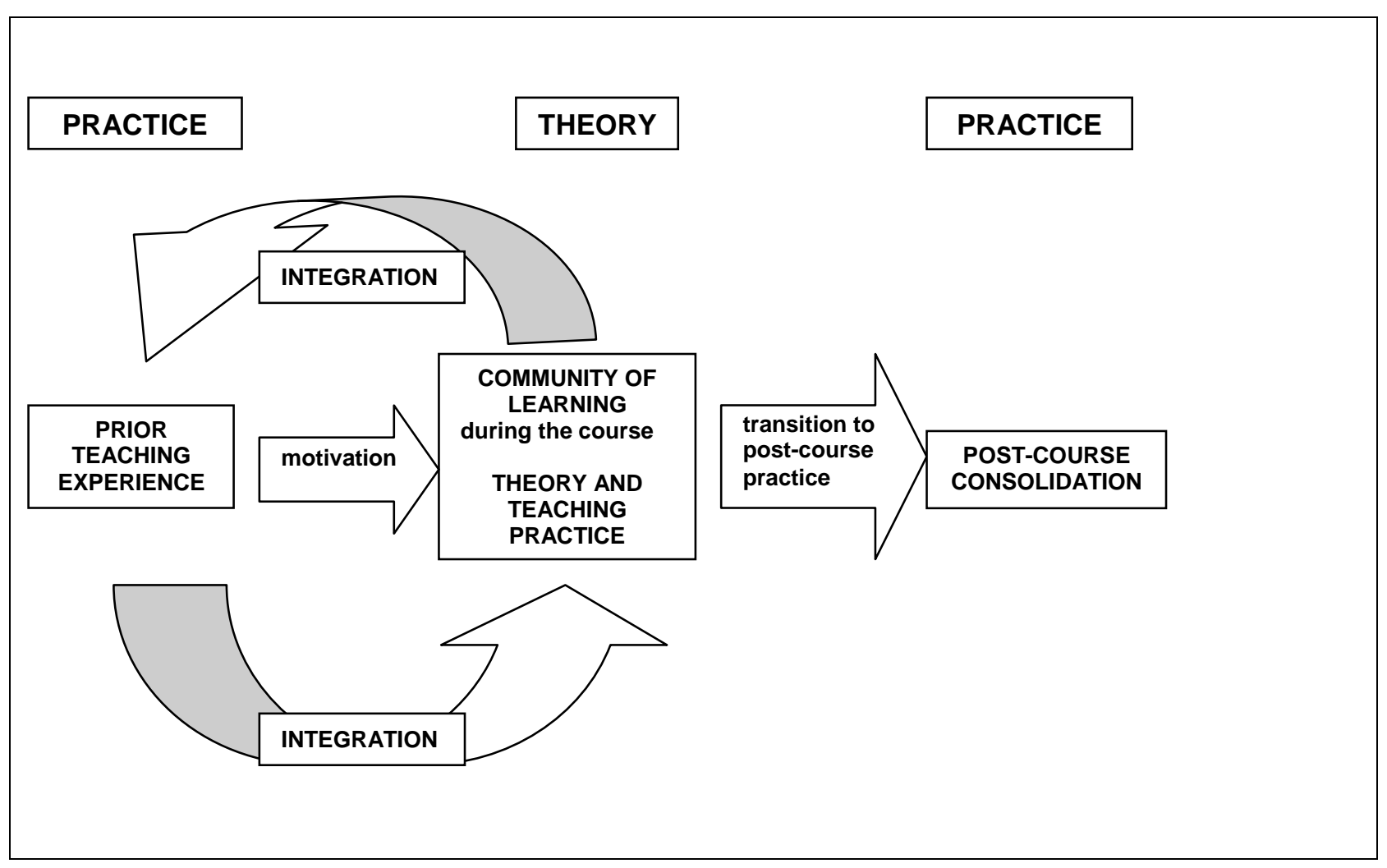

Figure 2: Sequence of factors on the DELTA CPD programme

The interview data suggests that CPD is most effective when these phases build upon each other, and when the two transition phases, at the beginning and the end of the course, are both smooth and pro-actively managed, that is, professional development is seen to have continuity. In the case of the DELTA, the pre-course transition has continuity if:

- participants are independently motivated (whether intrinsic or extrinsic)

- pre-course experience is sufficient to be a basis for effective learning during the course so that the course itself is perceived to be integrated and therefore more meaningful and relevant to participants

- the DELTA provides opportunities to bring learning from prior practice into the course experience, and to draw upon this during the course, again providing that sense of integration of theory and practice.

The post-course transition has continuity if DELTA graduates:

- can work in an establishment where their qualification and new-found skills are recognized

- $\quad$ can start to apply the learning from the course to their practice, because opportunities of the right kind are available

- have the chance for their increased motivation and enthusiasm to consolidate and flourish. 
A key point is that, while the community of learning on the course is vitally important, the impact of the course is determined not solely by the course itself but also by important pre- and post-course factors.

The DELTA is a hybrid model of professional development; it is an in-service course with characteristics of a pre-service professional education course in that it involves academic learning, pedagogical learning and classroom training. In contrast to the 'front-loading' of theory on many initial professional education courses, criticised by writers such as Eraut (1994) and Freeman $(1994,2002)$, the DELTA takes place after teachers have already started their teaching careers, with the result that the theoretical learning on the course is seen as more relevant and can be better integrated into their practical classroom experience. This is consistent with Eraut's claim that 'the potential of work-related ... mid-career professional education is underestimated' $(1994,12)$.

The second group of findings set out above identified as highly favoured modes of learning 'discussion, interaction, experiential learning, reflection, mentoring, modelling, observing other people teaching, and receiving constructive feedback'. These observations were made in the context of a retrospective study in which a key focus was sustained impact. If qualitative aspects of the process of learning were seen as so important by this group of HE learners, even such a long time after the learning experience, perhaps there is also a general question to be posed, in educational research, about the significance of the students' perceived views of the quality of the learning process for both immediate outcomes and sustained impact?

The findings reported above about the importance of 'integrated learning experiences' also provide food for thought. The evidence from the DELTA interviewees was clear: if there was plentiful opportunity within the professional learning HE programme to test out new theoretical ideas in practical situations - here, classroom teaching - then the theory itself was more likely to 'stick'.

In summary, the motivation for and receptivity to in-service learning generated by prior teaching experience, as many participants in this study have testified, together with the opportunity during the course to integrate theory and practice within an active community of learning, to which they also bore witness, provide a solid foundation for impact to take place and for this potentially to continue to influence teaching for years after the course.

\section{References}

Bennett, P. (1999) 'From secondary school blues to lifelong learning? - Aspects of the retrospective re-evaluation of formative educational experience by adults', International Journal of Lifelong Learning. 18 (3): 155-174.

Berliner, D. (1994) 'Teacher Expertise' in Moon, B. and Shelton Mayes, A. (eds) Teaching and Learning in the Secondary School, London: Routledge.

Bird, M., Ding, S., Hanson, A., Leontovitsch, A. and McCartney, R. (2005) 'There is Nothing as Practical as a Good Theory: an examination of the outcomes of a 'traditional' MA in Education for educational professionals', Journal of In-service Education. 31 (3): 427-453. 
Burchell, H., Dyson, J. and Rees, M. (2002) 'Making a Difference: a study of the impact of Continuing Professional Development on professional practice', Journal of In-service Education. 28 (2): 219-229.

Cope, P., Inglis, B., Riddell, S. and Sulhunt, O. (1992) 'The value of in-service degrees: teachers' long-term perceptions of their impact', British Educational Research Journal. 18 (3): 297-307.

Davies, R. and Preston, M. (2002) 'An Evaluation of the Impact of Continuing Professional Development on Personal and Professional Lives', Journal of In-service Education. 28 (2): 231254.

Day, C. (1999) Developing Teachers: the challenges of lifelong learning, London: Falmer.

Drever, E. (1995) Using Semi-structured Interviews in Small-scale Research, Edinburgh: The Scottish Council for Research in Education.

Eraut, M. (1994) Developing Professional Knowledge and Competence, London: Falmer.

Freeman, D. (1989) 'Teacher training, development and decision-making: a model of teaching and related strategies for language teacher education', TESOL Quarterly. 23 (1): 27-45.

Freeman, D. (1992) 'Language teacher education, emerging discourse, and change in classroom practice' in Flowerdew, J., Brock, M. and Hsia, S. (eds) Perspectives on Second Language Teacher Education, Hong Kong: City Polytechnic of Hong Kong.

Freeman, D. (2002) 'The hidden side of the work: Teacher knowledge and learning to teach', Language Teaching. 35: 1-13.

Fullan, M. (2001) The New Meaning of Educational Change, ( $3^{\text {rd }}$ edn). London: RoutledgeFalmer.

Gillham, B. (2000) Case Study Research Methods, London: Continuum.

Gomm, R., Hammersley, M. and Foster, P. (eds) (2000) Case Study Method, London: Sage.

Harmer, J. (1988) 'Swinging in from a chandelier - reminiscences of preparatory training courses' in Duff, T. Explorations in Teacher Training, London: Longman.

Hayes, D. (1995) 'In-service teacher development: some basic principles', English Language Teaching Journal. 49 (3): 252-261.

Huberman, M. (1995) The Lives of Teachers, London: Cassell. 
Johnston, B. (1994) 'Teacher education and the MA in ESL: the students' perspective' in Li, D.C.S., Mahoney, D. and Richards, J. (eds) Exploring Second Language Teacher Development, Hong Kong: City Polytechnic of Hong Kong.

Knight, P., Tait, J. and Yorke, M. (2006) 'The professional learning of teachers in higher education', Studies in Higher Education. 31 (3): 319-339.

Knowles, M. (1996) 'Andragogy: an emerging technology for adult learning' in Edwards, R., Hanson, A. and Raggatt, P. (eds) Boundaries of Adult Learning, London: Routledge in association with The Open University.

McDonough, J. and McDonough, S. (1997) Research Methods for English Language Teachers, London: Arnold.

Patton, M. (2002), Qualitative Research and Evaluation Methods, ( $\left.{ }^{\text {rd }} \mathrm{ed}\right)$. Thousand Oaks, California: Sage.

Powell, E. and Terrell, I. with Furey, S. and Scott-Evans, A. (2003) 'Teachers' Perceptions of the Impact of CPD: an institutional case study', Journal of In-service Education. 29 (3): 389 - 404.

Powell, J. (1985) 'The Residues of Learning: Autobiographical Accounts by Graduates of the Impact of Higher Education', Higher Education. 14: 127 - 147.

Powney, J. and Watts, M. (1987) Interviewing in Educational Research, London: Routledge.

Rhodes, C. and Houghton-Hill, S. (2000) 'The Linkage of Continuing Professional Development and the Classroom Experience of Pupils: barriers perceived by senior managers in some secondary schools', Journal of In-service Education. 26 (3): 423-435.

Roberts, J. (1998) Language Teacher Education, London: Arnold.

Ryan, R. and Deci, E. (2000) 'Intrinsic and extrinsic motivations: classic definitions and new directions', Contemporary Educational Psychology. 25: 54-67.

Singh, G. and Richards, J. (2006) 'Teaching and Learning in the Language Teacher Education Course Room: a Critical Sociocultural Perspective', RELC Journal. 37 (2): 149-175.

Strauss, A. and Corbin, J. (1998,) Basics of Qualitative Research, (2 ${ }^{\text {nd }}$ ed). Thousand Oaks, California: Sage.

Waters, A. (2006) 'Facilitating follow-up in ELT INSET', Language Teaching Research. 10 (1): $2-52$.

Waters, A. and Vilches, M. (2000) 'Integrating teacher learning: the School-Based Follow-up Development Activity’, English Language Teaching Journal. 54 (2): 126-134. 
Wenger, E. (1999) Communities of Practice: Learning, Meaning and Identity, Cambridge: Cambridge University Press.

Williams, R. (2005) 'The Role of Academic Study in Teachers' Professional Development', Journal of In-Service Education. 31 (3): 455-469.

\section{About the author}

Dr Joy Northcott is Senior Development Co-ordinator for Teacher Education at the English Language Teaching Centre (formerly IALS), University of Edinburgh.

Email: joy.northcott@ed.ac.uk 